\title{
A apropriação da cultura escrita em crianças do ensino fundamental: um estudo com a cultura e a literatura infantil indígena
}

\section{The appropriation of written culture in primary school: a study with indigenous culture and indigenous children's literature}

https://doi.org/10.34112/2317-0972a2020v38n78p51-65

\author{
Maria da Luz Lima Sales ${ }^{1}$ \\ ÂNGELA BALÇA ${ }^{2}$
}

RESUMO: A situação vivida pelos indígenas brasileiros impulsionou-nos à problemática desta investigação: promover a empatia e a cultura escrita em crianças do ensino fundamental, recorrendo à literatura infantil indígena. Os objetivos do estudo eram: conhecer concepções e atitudes dos alunos relativamente aos indígenas; orientar uma intervenção pedagógico-didática, apoiada na literatura infantil indígena, que ajudasse a modificar concepções e atitudes de natureza discriminatória; analisar em que medida essa intervenção serviu para aprofundar o conhecimento dos alunos acerca da cultura indígena, promovendo a apropriação da cultura escrita. Optou-se por um estudo qualitativo, numa aproximação à metodologia da design research. Como instrumentos de recolha de dados, elegeu-se a entrevista, a observação e as notas de campo. A amostra era constituída por uma turma do ensino fundamental de uma escola urbana do estado do Pará, Brasil. Os resultados da investigação apontaram para uma identificação, receptividade e entusiasmo das crianças à cultura e à literatura indígenas.

PALAVRAS-ChAVE: Escola; leitura; cultura e literatura infantil indígena.

1. Instituto Federal do Pará, Belém, Pará, Brasil.

2. Universidade de Évora, Centro de Investigação em Estudos da Criança da Universidade do Minho, Évora /Braga, Portugal. 
A apropriação da cultura escrita em crianças do ensino fundamental: um estudo...

ABSTRACT: The situation lived by Brazilian natives has led us to the problem of this research: to promote empathy and written culture in elementary school children, using indigenous children's literature. The goals of the study were: to know the students' conceptions and attitudes regarding the natives; to guide a pedagogical-didactic intervention, supported in the indigenous children's literature, that helped to change conceptions and attitudes of a discriminatory nature; to analyze the extent to which this intervention served as a means to deepen the students' knowledge about the indigenous culture, promoting the appropriation of written culture. We choose a qualitative study, in an approach to the methodology of design research. As instruments of data collection, the interview, the observation and the field notes were chosen. The sample was a class of elementary school from an urban school in the state of Pará, Brazil. The results of the research pointed to the children's identification, receptivity and enthusiasm for indigenous culture and literature.

KEYWORDS: School; reading; indigenous culture and indigenous children's literature.

\section{INTRODUÇÃO}

A lei 11645/2008 - que obriga o ensino, nas escolas brasileiras, de História e Cultura Afro-Brasileira e Indígena (BRASIL, 2008) - vem trazer a esperança de minorar o quadro de discriminação, no Brasil, contra indígenas. À vista disso, empenhamo-nos em utilizar a intervenção pedagógico-didática em sala de aula, através de oficinas, como meio de conhecimento da literatura infantil indígena para promover a formação de leitores, a apropriação da cultura escrita, a educação multicultural e uma reflexão sobre tais temas na escola.

Reconhecemos na educação multicultural bem como no poder da leitura e da literatura importantes caminhos para chegar ao Outro, ao mesmo tempo desenvolvendo no educando a consciência de mundo tão necessária à paz na escola e também na sociedade. Quanto mais nos aproximarmos desse Outro - que é indígena brasileiro - maior será a ocasião de desenvolver a empatia. A primeira etapa para se chegar à educação multicultural é promover o contato com outra cultura para desfazer os estereótipos que a cercam numa cortina de fumaça, impedindo o diálogo entre ambas.

Nossa proposta foi levar às crianças do quarto ano da escola básica histórias que elas desconheciam e lhes proporcionar a descoberta desse Outro que é indígena. Partimos do pressuposto que a expressão literária indígena deve ser valorizada, por proporcionar ao leitor oportunidade de conhecer novos pensamentos e novos valores, configurando-se como veículo de conscientização e empatia e formando-o, 
simultaneamente, como leitor. Nossa pretensão foi levar à escola autores e narrativas quase desconhecidos do grande público a fim de minorar a lacuna que há ainda hoje em relação à literatura infantil indígena no Brasil.

Nesse estudo, resultante de nossa Tese de Doutorado (SALES, 2019), na Universidade de Évora, Portugal, após expormos o referencial teórico, importante veículo de reflexão, destacamos inicialmente alguns aspectos da metodologia empreendida. Focamos, então, nas primeiras entrevistas semiestruturadas, seguidas de uma breve explanação de nossas oficinas, para depois expormos as segundas entrevistas semiestruturadas e, finalmente, concluir nosso estudo.

\section{REFERENCIAL TEÓRICO}

Inicialmente, nesse estudo, respaldamo-nos em Nussbaum (2005; 2015), Drobniewski (2012), Canclini (2015), Bhabha (2013), Freire (1987; 2016), Adorno (2000) e outros para, com seus pressupostos, refletirmos acerca de um pensamento com o qual compactuamos: a empatia para com o Outro. Tais autores nos propõem uma educação mais humanizada. Uns são mais explícitos, como é o caso de Nussbaum (2005; 2015), Drobniewski (2012) e Freire (1987; 2016); outros deixam, aqui e ali, traços de preocupação com os rumos que a escola segue presentemente e que nos levará, possivelmente, a um futuro incerto, conforme aponta Adorno (2000) em sua obra direcionada à educação.

A questão da empatia se insere em nossos propósitos no que concerne aos indígenas brasileiros, uma vez que são ainda hoje marginalizados; eles, porém, possuem uma cultura antiga e diversificada, não obstante ignorada pelos próprios brasileiros. Uma das consequências de tal desconhecimento é a discriminação e o racismo contra os nativos, o que nos motivou à investigação da cultura e da literatura infantil indígena e divulgação às crianças de uma escola amazônica. $O$ contexto atual vivido no país e em diversos pontos do globo exige dos cidadãos saírem de seu individualismo, olharem para o Outro e exercitarem a empatia.

Algumas das ideias errôneas acerca dos povos indígenas foram fincadas em nossas mentes durante séculos e fizeram com que esquecêssemos que os autóctones constituem uma importante parte do povo brasileiro, assim como os afrodescendentes, que nos transmitiram sua cultura, legando-a como marca a fim de formarmos nossa identidade. Não só o povo português faz parte dessa história, muitos outros povos deram sua contribuição para construirmos o que hoje chamamos de 
A apropriação da cultura escrita em crianças do ensino fundamental: um estudo...

Brasil. Os indígenas que aqui estavam no momento da chegada dos europeus nos deixaram uma das bases de nossa cultura, principalmente quando tratamos do Pará, da Amazônia e das crianças amazônicas.

Em meio a um país tão multicultural quanto o Brasil, há necessidade de levar à escola outras perspectivas, de autores literários que o cânone negligencia, mas que apresentam narrativas eternizadas por serem recontadas continuamente. Há, portanto, que se repensar a educação, refletindo os valores de igualdade e cidadania para todos. A construção de uma escola mais democrática se tornará viável mediante uma escola conscientizadora e humanizadora, empenhada na autonomia dos educandos (ADORNO, 2000; NUSSBAUM, 2005; FREIRE, 2016), lutando contra o preconceito e o racismo.

A obra literária, através de debates e reflexões, constitui importante motor para a sensibilização das pessoas que formam a sociedade, equilibrando-a, segundo Candido (2004). A literatura se torna "fator indispensável de humanização e, sendo assim, confirma o homem na sua humanidade (... )" (CANDIDO, 2004, p. 174). É ainda esse intelectual que afirma: "a literatura aparece claramente como manifestação universal de todos os homens em todos os tempos. Não há povo e não há homem que possa viver sem ela (...)" (CANDIDO, 2004, p. 174).

Assim, a literatura é um agente da educação multicultural a propiciar a empatia (NUSSBAUM, 2005; 2015; LOBO, 2008; SEBASTIÁN; GUTIÉRREZ, 2008; MORGADO; PIRES, 2010; DROBNIEWSKI, 2012; BHABHA, 2013) porque oportuniza o contato do leitor com o Outro, fazendo-o sentir outros sentires, com personagens que vivem vidas diferenciadas da sua, daquela experimentada por quem lê a obra literária, alargando sua mundividência. Este estudo, portanto, apresentou e trabalhou as obras da literatura infantil e a cultura indígena em uma sala de aula, com crianças do ensino fundamental, a fim de se desfazerem conceitos equivocados sobre povos indígenas, promover a empatia e fomentar a apropriação da cultura escrita.

\section{Metodologia}

Com base em preocupações ligadas à questão dos povos indígenas no Brasil contemporâneo e à questão da apropriação da cultura escrita pelas crianças, apresentamos nossa questão inicial - de que modo a intervenção pedagógico-didática do professor, ancorada na exploração da leitura e da literatura infantil indígena, pode contribuir para um maior conhecimento e respeito aos povos indígenas e 
sua cultura e, consequentemente, amenizar processos de discriminação em sala de aula? Como objetivos do estudo buscamos: conhecer as atitudes e concepções das crianças relativamente às populações e culturas indígenas; preparar e orientar uma intervenção pedagógico-didática, apoiada principalmente na literatura infantil indígena, que ajudasse a modificar as concepções e atitudes, especialmente as que se revelassem de natureza discriminatória; e analisar em que medida essa intervenção na sala de aula serviu como meio de aprofundar o conhecimento dos discentes sobre essa cultura, promovendo a apropriação da cultura escrita pela criança leitora.

Seguimos então a linha do estudo qualitativo, por investigar os discursos proferidos, indo ao lócus e averiguando com os sujeitos a compreensão da realidade através de suas representações, perscrutando sentimentos, inclinações, representações, receios e até preconceitos dos falantes, fazendo-os aflorar, o que pode nos ajudar a compreender a sociedade. Por desenvolvermos experimentações em sala de aula usando metodologias inovadoras, adequando-nos e afinando-nos ao longo do processo, optou-se por uma aproximação à metodologia da Design Research $(D R)$. A $D R$ pressupõe a ação em um contexto com um problema detectado e o estuda com o intuito de aplicar intervenções para solucioná-lo (FREITAS JUNIOR; MACHADO; KLEIN; FREITAS, 2015).

A recolha de dados se compôs de pesquisas em documentos, legislação brasileira, observações, notas de campo e entrevistas semiestruturadas.

Oito foram as partes que compuseram a investigação: a) preparação do roteiro e da primeira entrevista semiestruturada, com sua aprovação; b) aplicação da entrevista; c) análise desta; d) elaboração dos planos das oficinas; e) intervenções na sala de aula (dez oficinas utilizando-se sempre a literatura infantil indígena e alguns artefatos desta cultura); f) preparação do roteiro e da segunda entrevista semiestruturada, com sua aprovação; g) aplicação da segunda entrevista; e h) análises dos dados.

Utilizamos, inicialmente, como base de nossos estudos, leis como a Constituição de 1988; a lei 11645/2008, a qual torna obrigatório nas escolas básicas o ensino da cultura, da história indígena e afrodescendente; normatizações referentes à escola brasileira, a exemplo da Lei de Diretrizes e Bases da Educação Nacional, dos Parâmetros Curriculares Nacionais, da Base Nacional Comum Curricular e de políticas educacionais como o Programa Nacional Biblioteca Escolar, o Programa Nacional do Livro Didático e o Sistema Municipal de Biblioteca Escolar.

Com a entrevista semiestruturada, vemos as marcas dos discursos hegemônicos incrustadas nas falas, suas subjetividades e fragilidades, ajudando-nos a 
A apropriação da cultura escrita em crianças do ensino fundamental: um estudo...

enxergar e compreender tais representações. Em vista disso, elaboramos os roteiros para duas partes das entrevistas, uma antes da intervenção e outra logo em seguida a ela. Buscamos nossas respostas em alunos do quarto ano do Ensino Fundamental, na faixa etária de nove e dez anos, importante idade para alguns autores (KOEPKE, 2014), que a explicam como fase de início de uma compreensão maior dos fatos experienciados.

A intervenção pedagógico-didática se sucedeu em quatro meses, de fevereiro a junho de 2017, com dez oficinas realizadas às quintas e sextas-feiras, de 7 h3o às $9 h_{30}$ da manhã, em uma sala de aula com 28 alunos. Porém, a amostra do nosso estudo foi constituída apenas por 17 crianças, por motivo de falta de assiduidade de algumas delas. Resolvemos designar as sessões como oficinas para diferenciá-las das aulas comuns, dando-lhes uma configuração mais ativa da parte do alunado, com maior participação em atividades lúdicas.

O corpus de nosso estudo e prática na escola se formou de histórias de autores indígenas, a exemplo de Daniel Munduruku (o escritor indígena brasileiro mais conhecido), Yaguarê Yamã e Kaká Jecupé; também compuseram esse rol escritores não indígenas, como Clarice Lispector, Ana Maria Machado, Juraci Siqueira e Marion Villas Boas, com fábulas ou histórias de animais, lendas, mitos e demais narrativas.

Enumerando-as, utilizamos nas oficinas dez narrativas contadas pelos próprios escritores indígenas. De Kaká Werá Jecupé (2007): O buraco da onça, Iauaretê e a anta, O pajé e o ratinho e Iauaretê e o jabuti; de Daniel Munduruku (2001; 2006; 2009): Maracanã, O saber das avós, As serpentes que roubaram a noite; de Yaguarê Yamã (2001; 2014): Sobre a origem do mundo, Yaguarãboia, a mulher-onça e O fantasma da casa abandonada. E mais cinco recontadas por escritores não indígenas: Ana Maria Machado (2004): O Veado e a Onça (a mesma Iauaretê e a anta, de Kaká Werá Jecupé, com pequenas variações); Clarice Lispector (1999): O pássaro da sorte; Marion Villas Boas (2013): Jabuti e a anta e Jabuti e a onça; e Juraci Siqueira (2016): O mito da criação dos rios da Ilha de Marajó.

As primeiras entrevistas nos serviram, entre outros objetivos, para observação da receptividade dos alunos acerca dos povos indígenas e de sua cultura. Em seguida a elas, analisamos os dados e continuamos com a intervenção pedagógico-didática realizada pela professora investigadora, enquanto fazíamos anotações do andamento de todas as oficinas. Tratava-se de observações e notas de campo feitas após cada oficina também pela investigadora. Em cada uma das sessões em sala de aula utilizamos histórias de livros de escritores indígenas e não indígenas que também 
recontam histórias de nossos nativos. Depois da intervenção pedagógico-didática, demos prosseguimento para as segundas entrevistas, seguidas de sua análise de dados e comparação de ambas, para perceber se houve alguma modificação nas concepções e atitudes de natureza discriminatória da parte dos sujeitos-crianças, se houve um aprofundar de conhecimentos acerca da cultura indígena, promovendo a apropriação da cultura escrita pela criança.

\section{Primeira entrevista}

A primeira entrevista semiestruturada continha 13 questões e pretendia identificar o nível de conhecimento das crianças acerca da cultura indígena, para posteriormente promover a leitura e a educação multicultural no meio escolar, estimulando maior respeito pelos povos indígenas e sua cultura. Cada uma foi designada com uma letra do alfabeto, de A a Q. Essa entrevista as encontrou inicialmente acanhadas, certamente por se tratar de um primeiro contato mais próximo, afinal, havíamos nos reunido apenas uma única vez antes, no dia em que nos apresentamos a elas.

Ao estudar a criança de nove anos, Koepke (2014) acredita que esta não possui ainda a capacidade de abstração em profundidade, principalmente quando lida com problemas complexos. Por se tratar de entrevistas semiestruturadas, tais aspectos foram observados nas crianças ouvidas, pois esse tipo de entrevista proporciona maior liberdade às respostas propostas, sem seguir as questões rigidamente, deixando os falantes livres para falar abertamente.

Precisamos saber de nossas crianças se elas conheciam algo da cultura indígena e se já haviam visto algum indígena antes; ao perguntarmos a uma delas o que pensava acerca destes, afirmou-nos que os "achava um pouco preguiçosos". Outra, quando questionada como reagiria ao encontrar um indígena na rua, replicou: "Eu até o trataria bem", levando-nos a supor que seria uma concessão tratar um indígena bem. Bakhtin (2000) nos fala de tais palavras ocultas ou semiocultas que o falante profere, "com graus diferentes de alteridade" (BAKHTIN, 2000, p. 318). É difícil ser empático com o outro quando ele é muito diferente de nós, ainda mais se não sabemos nada sobre ele antes.

Ao fazer um apanhado dos termos utilizados pelos discentes na descrição acerca dos indígenas, obtivemos um resultado esperado. Clichês como: "sem roupa", "pintados”, “com penas", "palhas", "flechas”, "eles comem eles mesmos”, "tatuagem”, “tem 
um negócio aqui grandão" (botoque), mostraram o desconhecimento que gera estereótipos, os quais formam o imaginário sobre indivíduos e cultura indígenas.

Os entrevistados apresentaram ora uma visão romântica dos indígenas ("A pessoa [indígena] pode fazer tudo o que ela quer", "são livres na vida deles, (...) podem fazer o que eles quiserem") ora os relataram como selvagens, atrasados, seres que não têm nada a oferecer ou a ensinar a nossa sociedade: "para aprender a ler e escrever, falar com a gente, para ele conseguir passar de ano, pra ele saber como são as coisas”, “(...) porque eles iam saber estudar”, "a gente pode ajudar melhor eles a terem mais amigos", "porque eles estariam estudando, estariam aprendendo a ler". Também alguns os ignoram completamente: "lá não tem escola", "[o indígena] é negro", "é negro, (...) cabelo enroladinho", "ele é preto", "loiros, os olhos podem ser azuis, verdes...," "o olho azul", “...ele usa tatuagem”.

A maioria das crianças demonstrou ser receptiva para com os indígenas quando lhes foi perguntado se gostariam de conhecer uma aldeia indígena. Revelaramse muito curiosas e interessadas em saber de sua cultura, sua habitação, seus costumes, sua vida mais livre, em contato com a natureza e os animais, daí por que se identificaram com os povos indígenas: "queria ver eles caçando", "[vi] na $\mathrm{TV}$ e achei legal", "gosto de saber o que eles fazem", "eu queria ver como as casas são, como são as brincadeiras".

A criança é aberta ao novo e não demonstra preconceito ou racismo a não ser que tenha sido educada para rejeitar ou discriminar o Outro. Essa abertura podemos perceber nas falas: "porque ia poder tomar banho nos igarapés 3 ", "porque eu gosto do mato" " "lá [nas aldeias] é legal (...) dá pra brincar de qualquer coisa lá. Lá é maior."

Considerando que ainda não havíamos empreendido as oficinas, tais respostas nos serviram como indicadores de que as crianças necessitavam conhecer realmente a cultura indígena, e também de que a lei $11645 / 2008$ precisa sair do papel e habitar as escolas brasileiras.

\section{As oficinas}

Iniciamos as intervenções pedagógico-didáticas, consubstanciadas em dez oficinas, após a primeira entrevista, já cientes de que os sujeitos de pesquisa, apesar de demonstrarem ignorância em relação à cultura indígena, achavam-se receptivos em

3. Igarapé: rio. Em tupi: caminho das águas. 
relação a ela. Cada oficina foi elaborada de modo a apresentar atividades diferenciadas com recursos didáticos variados e muita leitura mediada, que promovesse a reflexão acerca da cultura e filosofia indígenas bem como a leitura e o conhecimento da literatura infantil indígena; enfim, a apropriação da cultura escrita.

Nas oficinas, as práticas de caráter pedogógico-didático incorreram em leituras da literatura infantil indígena e dinâmicas ativas e inovadoras, sempre estimulando as crianças a participar delas bem como das reflexões baseadas nos temas, a partir do estudo das obras literárias. Empreendemos, outrossim: contação de histórias, visionamento de vídeos, áudio de uma canção guarani com a cantoria das crianças, fabricação de objetos (casa de papel, animal de massinha), desenhos (de charges, história em quadrinhos), caça-palavras indígena, palavras cruzadas, um jogo de origem indígena, pintura corporal ou grafismo, dobradura de papel, contato com artefatos e adereços exclusivamente originários da cultura indígena.

No momento inicial de cada sessão havia a contação de histórias promovida pela professora investigadora em determinadas ocasiões e, noutras, os alunos realizavam a leitura silenciosa ou oral. Esses momentos eram seguidos de discussão sobre aspectos das narrativas e os discentes contribuíam manifestando suas impressões acerca dos textos.

Durante as oficinas houve alternância na apresentação de histórias contadas por escritores indígenas e não indígenas, como já relatado. No geral, eram feitas duas leituras em momentos diferentes de cada sessão, de modo que os alunos pudessem compreender e abstrair os elementos de cada texto antes que se iniciasse a contação da história seguinte. As atividades de cada dia eram feitas de acordo com o tema da oficina e diretamente relacionadas à narrativa apresentada naquela ocasião.

Atividades lúdicas encerravam cada oficina para produzir nas crianças um efeito agradável, a fim de que elas voltassem na outra semana e vissem na escola bons momentos de aprendizado e lazer. Era um momento de descontração, pelo qual as crianças já esperavam entusiasmadas, pois se mostrou como rotineiro tornar a oficina mais divertida e desejada. Simpatizantes das ideias de Tolstói (2005), cuja pedagogia propiciava uma "aprendizagem participante e criativa" (TOLSTÓI, 2005, p. 16), entendemos que toda aula para crianças deve ser motivadora e oferecer a oportunidade para elas se descontraírem e aprenderem brincando.

Ao final de cada oficina, sempre estimulávamos os alunos a buscarem na biblioteca da escola textos de literatura infantil indígena para serem lidos em casa e posteriormente comentados em sala de aula. 
A apropriação da cultura escrita em crianças do ensino fundamental: um estudo...

Segunda ENTREVISTA

A segunda parte das entrevistas se realizou após a intervenção pedagógico-didática e objetivava reconhecer o nível de conhecimento dos educandos no tocante à cultura indígena e promover a educação multicultural com mais consideração pelo povo indígena. Foram um total de quinze perguntas, divididas novamente em dois blocos: a) conhecimento: aprofundar o conhecimento da cultura indígena; $\mathrm{e}$ b) respeito: possibilitar a educação multicultural com mais consideração pelo povo indígena e por sua cultura, de maneira que fosse possível esquematizar as respostas para posterior análise. Optamos novamente por utilizar o mesmo código alfabético da entrevista anterior com cada entrevistado.

Iniciamos essa segunda rodada de perguntas desejando saber o que as crianças pensavam acerca de ideias que são divulgadas sobre os indígenas, como a de que eles se alimentam de carne humana ou são preguiçosos. A maioria dos discentes se posicionou por não concordar com tais ideias, embora alguns não tenham conseguido desenvolver um raciocínio claro sobre a questão, provavelmente em decorrência da imaturidade natural da idade. Ilustrando os cinco séculos de preconceitos ligados à cultura indígena, três alunos compactuaram com as ideias preconceituosas expostas na pergunta, certamente por ouvirem discursos tão veiculados na sociedade, que ainda associam o indígena ao canibalismo e à preguiça.

Merecem destaque as respostas ao seguinte questionamento, o qual inquiria se a criança gostara de ter conhecido algo mais sobre a cultura indígena. Houve unanimidade na aceitação e satisfação em conhecer a cultura e literatura indígenas. Determinadas crianças manifestaram: "Ahã. Porque é legal. Tem gente que acha muito chato trabalhar com os índios, tem gente que gosta até de escravizar os índios. Mas tem gente que gosta deles".

Alguns alunos enfatizaram que gostaram de aprender sobre a cultura indígena. Um deles até destacou os detalhes mais significativos do aprendizado: "Sim, porque a gente aprendeu as palavras que eles usam. A gente aprendeu as palavras indígenas, a gente soube dos índios". De modo geral, os discentes apontaram as oficinas como benéficas; nelas, obtiveram a oportunidade de conhecer novas palavras, narrativas diferenciadas, um jogo, brincadeiras divertidas - experiência considerável em sua formação como cidadãos.

Uma de nossas questões fez referência ao conhecimento das crianças sobre a autoria dos textos indígenas. A maioria dos entrevistados (quatorze dos 
dezessete) admitiu ter conhecido; entretanto, alguns, provavelmente em virtude da complexidade das palavras indígenas, não conseguiram se lembrar dos nomes com exatidão. Outros, apesar das dificuldades da nomenclatura dos escritores ameríndios, souberam citar com precisão o nome de Kaká Jecupé - autor de quatro das narrativas escolhidas para a oficina.

Outro autor lembrado pelas crianças foi Daniel Munduruku. Os textos sobre onças foram os campeões no gosto dos alunos, que inclusive citaram os mais impactantes, lembrando-se da trama e dos nomes complexos de personagens como Iauaretê e Yaguarãboia. Entre os dezessete entrevistados, apenas três não se lembraram de nenhum texto, apesar da contação de histórias em sala de aula.

Quando lhes foi indagado sobre o que pensavam da pintura corporal ou grafismo, a maior parte das crianças demonstrou empolgação em conhecer essa arte. Uma das respostas de um dos entrevistados a essa mesma questão se revelou bastante apreciável: "Eu gostei muito [ênfase]. Porque quando eu cheguei lá em casa, a mamãe disse que eu não 'tava' parecendo eu mesma, parecia que eu tinha ido na tribo do meu avô, e me pintaram todinha!”. Tal fato já fora detectado de antemão pela professora investigadora, uma vez que, durante a realização dessa atividade lúdica, os discentes se mostraram alegres e ansiosos para que chegasse logo o momento de ter os grafismos pintados em sua pele. Curiosamente, um aluno, que inicialmente não desejara participar desta atividade, ao observar a animação de seus colegas, mudou de opinião e teve o rosto pintado, assim como os demais.

A penúltima pergunta indagava sobre a possibilidade de a criança se encontrar com um indígena. Dos dezessete entrevistados, a maioria respondeu positivamente, dizendo que tratariam o indígena bem. Não obstante, as justificativas foram as mais diversas, tais como a de um aluno, que afirmou desejar ser amigo deles, ensejando também ser um indígena. Outrem declarou que não devemos maltratá-los e ainda outro proferiu que lhes daria um presente.

Os entrevistados demonstraram, explicitamente ou de modo velado, que admiram o estilo de vida indígena - ao respeitar os animais e a natureza, consideram positivamente os índios e reconhecem o seu direito de lutar por suas terras. Algumas crianças, que se mostraram mais empedernidas na visão estereotipada do indígena, em suas últimas respostas confirmaram a nós uma sensibilização pelos índios e sua cultura. 
A apropriação da cultura escrita em crianças do ensino fundamental: um estudo...

\section{Conclusões}

Ao observar os objetivos das entrevistas junto às intervenções e tendo como norte a questão inicial de nossa investigação, isto é, um trabalho sistemático com aporte principal da literatura infantil indígena na escola básica, a fim de tornar a cultura indígena mais visível e promover a empatia nos discentes bem como a sua apropriação da cultura escrita, levamos à escola uma cultura que, apesar de ter seu valor, sofre processos de discriminação junto a povos que formaram a nação brasileira.

Uma gama de autores nos fizeram crer que é possível uma educação mais humanizada, aqui também chamada de educação multicultural. Todos eles estão, de algum modo, comprometidos com uma educação diferenciada e conscientizadora, que possa dar conta do futuro que se espraia; para isso, no entanto, devemos plasmar nossas crianças com o barro da solidariedade e da cidadania.

O papel da literatura é preponderante porque, com ela, podemos enxergar além das aparências e sair de nosso mundo cercado de conformismos. A reflexão vem da leitura atenta e da compreensão do que está escrito. Lemos no livro, no Outro e imediatamente comparamos com o que pensamos e vemos em nós e na sociedade. A leitura nos força a enxergar o que está encoberto.

Confirmamos, em nossos estudos, com a primeira entrevista, haver um preconceito meio velado e um grande desconhecimento dos indígenas, nos discursos dos sujeitos entrevistados, mas verificamos também o desejo que nasce da curiosidade de conhecer algo mais desses povos, de sua cultura e a disposição de recebê-los bem.

Os alunos não conheciam nenhum autor ou obra de literatura infantil indígena antes de nossa intervenção pedagógico-didática, porém, a partir do momento em que tiveram contato com essas histórias e as leram, notamos que as apreciaram; e mesmo em relação aos próprios indígenas, seu jeito de ser e de viver foi apreciado e admirado. Houve identificação; daí a boa recepção para com a cultura que lhes apresentamos, mostrando-se sensíveis aos dramas vividos pelos indígenas, como a luta pelos territórios e por sua cultura milenar. Mas o que mais ficou patente na preferência das crianças foram as narrativas indígenas, contadas ou lidas.

A boa receptividade das oficinas foi perceptível, possivelmente por trazer elementos inéditos, como a literatura e os artefatos pertencentes à cultura indígena. A maior parte da turma se recordou das histórias lidas na aula anterior; houve evolução também na leitura oral praticada pelos alunos, uma vez que, nas primeiras sessões, eles se mostravam titubeantes no momento de ler em voz alta e, posteriormente, 
apresentaram-se mais desenvoltos e empolgados na leitura compartilhada, o que solidificou em nós a crença de que tais atividades são essenciais para o desenvolvimento do potencial dos jovens leitores e precisam ser estimuladas continuamente na escola.

Contrapondo as duas entrevistas e levando em consideração a importância das oficinas, constatamos que a intervenção pedagógico-didática foi profícua, haja vista que anteriormente os discentes demonstraram total ignorância com relação aos povos indígenas e sua cultura, mas, após as oficinas, puderam conhecer vocábulos, narrativas e instrumentos musicais, entre outros artefatos e aspectos da riqueza milenar desses povos.

As expressões de carinho e de boa receptividade observadas nas segundas entrevistas suplantaram aquelas de caráter depreciativo detectadas nas primeiras entrevistas acerca dos indígenas. Tanto que as atividades lúdicas de culminância, sempre promovidas ao final de cada sessão, deixaram claro a participação total das crianças, comprovando o sucesso obtido na intervenção pedagógico-didática, leitmotiv principal de nossa investigação.

Terminamos nosso estudo, novamente, com Candido (2004) e seu pensamento sobre o poder da literatura (e da cultura, acrescentamos nós) na luta contra a discriminação e o racismo: "a literatura pode ser um instrumento consciente de desmascaramento, pelo fato de focalizar as situações de restrição dos direitos, ou de negação deles, como a miséria, a servidão, a mutilação espiritual" (CANDIDO, 2004, p. 186).

Acreditamos assim que os objetivos dessa investigação foram concretizados, contribuindo para a apropriação da cultura escrita, por parte das crianças, e para o seu conhecimento e modificação de algumas concepções e atitudes perante a cultura e perante os próprios povos indígenas.

\section{REFERÊNCIAS}

ADORNO, T. W. Educação e emancipação. Tradução de W. L. Maar. Rio de Janeiro: Editora Paz e Terra, 2000.

BAKHTIN, M. Estética da Criação Verbal. Tradução de P. Bezerra. São Paulo: Martins Fontes, 2000. BHABHA, H. O local da cultura. Tradução de M. Ávila, E. L. Reis, G. R. Gonçalves. Belo Horizonte: UFMG, 2013.

BRASIL. Lei n. 11645/2008, de 10 de março de 2008. Altera a Lei n. 9394, de 20 de dezembro de 1996, modificada pela Lei n. 10639, de 9 de janeiro de 2003, que estabelece as diretrizes e bases da educação nacional, para incluir no currículo oficial da rede de ensino a obrigatoriedade da 
A apropriação da cultura escrita em crianças do ensino fundamental: um estudo...

temática "História e Cultura Afro-Brasileira e Indígena”. Diário Oficial da União, Brasília, DF, 11/3/2008, Seção 1, p. 1 .

CANCLINI, N. G. Culturas híbridas: estratégias para entrar e sair da Modernidade. São Paulo: Editora da Universidade de São Paulo, 2015.

CANDIDO, A. O direito à literatura. In: Candido, A. Vários Escritos. São Paulo, Brasil: Duas Cidades, 2004. p. 169-191.

DROBNIEWSKI, H. M. La educabilidad de las emociones y su importancia para el desarrollo de un ethos democrático: La teoría de las emociones de Martha Nussbaum y su expansión a través del concepto de autorreflexión. Valencia: Universidad de Valencia, 2012.

FREIRE, P. Pedagogia do oprimido. Rio de Janeiro: Editora Paz e Terra, 1987.

FREIRE, P. Conscientização. São Paulo: Cortez, 2016.

FREITAS JUNIOR, J.; MACHADO, L.; KLEIN, A.; FREITAS, A. Design Research: Aplicações práticas e lições aprendidas. Revista de Administração FACES Journal, Belo Horizonte, MG, v. 14, n. 1, jan./mar. 2015, p. 95-116. Disponível em: http://www.fumec.br/revistas/facesp/article/ view/1999. Acesso em: o5 set. 2019.

KOEPKE, H. A criança aos 9 anos: a queda do paraíso. Tradução de C. T. Bottura. São Paulo: Antroposófica, 2014.

LOBO, I. T. Coordenadas teóricas y contextuales de la educación literaria ante el desafio intercultural. In: LOBO, I. T. (Org.). Leer la Interculturalidad. Santander: Universidad de Cantabria, 2008. p. 38-87.

MORGADO, M.; PIRES, M. N. Educação Intercultural e Literatura Infantil: vivemos num mundo sem esconderijos. Lisboa: Colibri, 2010.

NUSSBAUM, M. C. El cultivo de la humanidad: una defensa clásica de la reforma en la educación liberal. Barcelona: Paidós, 2005.

NUSSBAUM, M. C. Sem fins lucrativos: por que a democracia precisa das humanidades. Tradução de F. Santos. São Paulo: Martins Fontes, 2015.

SALES, M. L. A literatura infantil indígena como meio de promoção da educação multicultural. A intervenção didática em uma escola de Belém (Brasil). 2019. Tese (Doutoramento em Ciências da Educação) - Instituto de Investigação e Formação Avançada, Universidade de Évora, Évora, 2019.

SEBASTIÁN, R. G.; GUTIÉRREZ, B. R. Aproximaciones y propuestas para una didática de los valores a través de las lecturas literarias. In: LOBO, I. T. (Org.). Leer la Interculturalidad. Santander: Universidad de Cantabria, 2008. p. 88-113.

TOLSTÓI, L. Contos da nova cartilha: primeiro livro de leitura. Cotia: Ateliê Editorial, 2005.

SOBRE AS AUTORAS:

Maria da Luz Lima Sales é graduada em Letras (Universidade Católica do Paraná), Mestre e Doutora em Ciências da Educação (Universidade de Évora, Portugal). É professora/pesquisadora no Instituto Federal do Pará. Tem experiência na área de Educação Literária, ensino de literatura brasileira, com pesquisa 
em literatura infantil, e literatura infantil indígena no grupo GELLA (Grupo de Estudos Literários e Linguísticos da Amazônia) pelo CNPq.

E-mail: maria.luz@ifpa.edu.br.

Ângela Balça é licenciada em Línguas e Literaturas Modernas - Estudos Portugueses (Universidade Nova de Lisboa) e doutorada em Ciências da Educação (Universidade de Évora). É professora/pesquisadora na Universidade de Évora e na Universidade do Minho. Tem experiência na área de Educação Literária com pesquisa nos seguintes temas: Formação de Leitores Literatura Infantil e Ensino da Língua Materna.

E-mail:apb@uevora.pt.

Recebido em 02 de agosto de 2019 e aprovado em 25 de novembro de 2019. 